Vol. 11, No. 41, October, 2016, 1285-1297

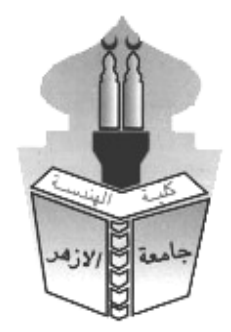

\title{
EFFECT OF ADDING SHORT BLADES ON CENTRIFUGAL PUMP PERFORMANCE AND DYNAMIC STABILITY
}

\author{
Ibrahim R. Teaima and M. A. Hashim \\ Researcher, Mechanical and Electrical Research Institute, National Water Research Center, \\ Egypt
}

\begin{abstract}
Centrifugal pumps are used extensively for hydraulic transportation of liquids over short to medium distance through pipelines where the requirements of head and discharge are moderate. The improvement of centrifugal pumps characteristics is important reduce the consumption of energy. One possible modification is to break down the circulation near the impeller exit using shorted blades. Numerical simulation and experimental verification are used to investigate the effects of short baled geometry on flow field and dynamic analysis of centrifugal pump. The model pump has a design specific speed of $23.75 \mathrm{rpm}$ and an impeller with 7 blades. The short blade length factor $L_{b}$ ratio varied from $0.16,0.25$ and 0.3 respectively from the impeller blade length. Other geometric parameters are kept constant. The inner flow fields and characteristics of the centrifugal pumps with different short blade lengths are simulated and predicted using commercial code Fluent under Ansys Ver.14.5. A test rig for testing centrifugal pump with standard impeller and three impellers of different shorted blade sizes is constructed. The head, flow rate and shaft power are evaluated for each pump configuration to show the effect of these shorted blades sizes on pump performance. When add short blades, with length ratio $L_{b}=0.25$, the vibration level increased to reach 1.32 $\mathrm{mm} / \mathrm{s}$. A $30 \%$ increase in vibration level is found compared to impeller without short blades; whoever, vibration level is still within the allowable level according to the international standards (ISO 10816-3). High frequency analysis shows that, the bearing is affected by adding short blades. For impeller with additional short blades between the main blades, $H$ increased by $3.78 \mathrm{~m}(11.68 \%)$, and $\eta$ by $(6.95 \%)$. The power consumption in the case of blade length ratio $L_{b}=0.25$ approximately constant compared with the total energy consumption without impeller short blades with no power saving. Time averaged numerical results are compared with the experimental performance curve and good agreement has been achieved.
\end{abstract}

Keywords: Short blades; impeller exit; centrifugal pump; numerical simulation; vibration level.

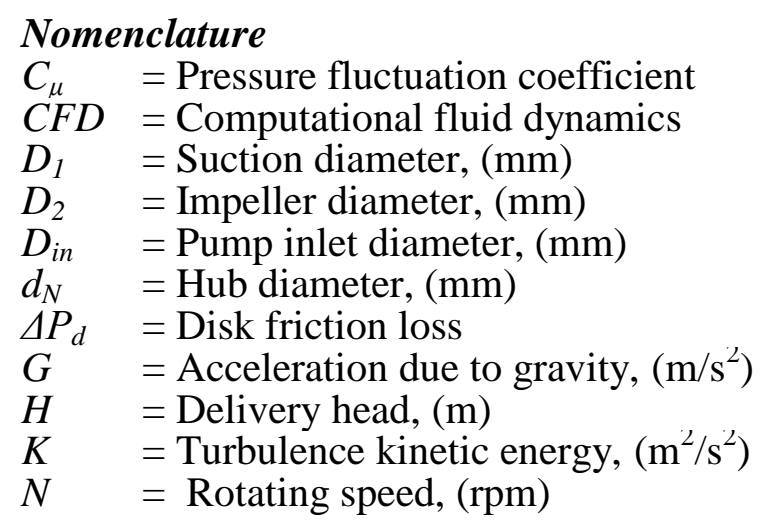


$M \quad=$ Impeller torque, $(\mathrm{Nm})$

$L \quad=$ Turbulence length scale, $(\mathrm{mm})$

$L_{b} \quad=$ Main length factor

$L_{m b} \quad=$ Main blade length, $(\mathrm{mm})$

$L_{m s} \quad=$ Short blade length, $(\mathrm{mm})$

$n_{s} \quad=$ Specific speed, $(-)$

$P_{e} \quad=$ Water power, (watt)

$P_{i n} \quad=$ Total pressure of impeller inlet, $(\mathrm{Pa})$

$P_{\text {out }} \quad=$ Total pressure of volute outlet, $(\mathrm{Pa})$

$Q \quad=$ Flow rate, $\left(\mathrm{m}^{3} / \mathrm{s}\right)$

$u_{i n} \quad=$ Inlet velocity, $(\mathrm{m} / \mathrm{s})$

$Z \quad=$ Blade number

\section{Greek symbols}

$\beta=$ Baled angle, (degree)

$\varepsilon \quad=$ Turbulence dissipation rate

$\rho \quad=$ Density, $\left(\mathrm{kg} / \mathrm{m}^{3}\right)$

$\eta_{h} \quad=$ Hydraulic efficiency, $(\%)$

$\eta_{v} \quad=$ Volume efficiency, $(\%)$

$\eta \quad=$ Total efficiency, $(\%)$

$\omega=$ Angle velocity, $(\mathrm{rpm})$

\section{Subscripts}

$$
\begin{array}{ll}
1 & =\text { Inlet impeller } \\
2 & =\text { Outlet impeller } \\
\text { in } & =\text { Inlet } \\
\text { out } & =\text { Volute outlet }
\end{array}
$$

\section{INTRODUCTION}

With the wide use of pumps in various economic activities, performance improvement would have a significant value in terms of energy conservation. Suitable design of pump impeller blade plays an important role in pump performance improvement. In the centrifugal pumps, the interface between the flow leaving the impeller and entering the volute made turbulent pressures which growth toward the inlet and the discharge of the pump. These turbulences would mainly be close to the blade passage frequency showing high severity near the volute tongue and at impeller exit flow. Short blades technique is one of the techniques common used in turbo-machinery design and application [1-3]. Moisés et al. [4] conducted the investigation of the theoretical study on turbulence pressure reduction in centrifugal pumps. Affecting of radial gap and short blades gives the largest pressure turbulence happens at the impeller exit closed to near the volute tongue. Comparisons among the pump configurations show the importance of adding intermediary blades in the impeller, giving good results and being more reliable for decreasing turbulence levels and also feed with a suitable increase of radial gap. Suitable boundary conditions are essential to predict effectively the pressure turbulence especially at the pump discharge. The selection of outflow boundary condition at the outlet of the domain is indicated by the truth that the velocity and pressure are not known and imposing a pressure outlet condition will have a numerical impact on the pressure turbulence. Yang Sun et al. [5] carried out theoretical research on effects of splitter blades to the influence of pump as turbine. Comparison of estimated impeller efficiencies with and without short blades showed that performance increased and its required pressure head is decreased when short blades are added to impeller flow passage. Investigation into unsteady pressure head field within volute shows that the absolute pressure linear decreases along the volute flow passage. The maximum amplitude value of pressure turbulence within volute is located before the volute tongue. When short blades are added to the impeller, there is an obvious decrease of pressure turbulence. For impeller without short blades, the maximum value of pressure pulsation within impeller occurs in the center of impeller. When short 
blades are added, its amplitude of pressure turbulence is rapidly decreased. Also it is demonstrated that the pressure turbulence within the two flow crosses caused by the increase of short blade to impeller flow channel is almost the same. Spence and Amaral-Teixeira [6] worked in the investigation of the pressure turbulence in a centrifugal pump, measuring in different positions the pulsations levels and finding strong values at the impeller outlet. Moreover, the asymmetric shape of the volute and tongue is a source of circumferential distortion of pressure distribution according to Asuaje et al. [7], who carried out experiments that showed the effect of volute tongue causing an unsymmetrical flow sectors and un equal pressure distribution at impeller side. Many works in experimental and theoretical study have been done helping the understanding of the geometrical variables effect and operating classifications and their relation with the pressure distribution behavior aiming to decrease the noise levels inter the pump. One of such parameters is the increasing of the number of blades which has toward impact on the acoustic characteristics but decreases the hydraulic pump performance, [7]. Also Kergourlay et al. [8], who experimented for different flow rates exist of splitter blades, shows that this final solution has a good effect on the pressure turbulence reduction at the exit flow pump. Also he found experimentally and theoretically that the use of center shortens blades allows a good peripheral pressure distribution. Minable, Miyamoto et al. [9], who worked on experimental measurements in a semi open and a fully open impeller with splitter blades, showed that with splitters the blade loadings to become smaller, and the absolute peripheral velocities and total pressures become slightly bigger than those impellers without splitter blades, thus obvious the effect of the splitter blades on static pressure. Another important view about pressure turbulence is the working point, ParrondoGayo et al. [10] denoted out through experimental measurements in the volute of a centrifugal pump the effect of working point on pressure distribution at the blade passage frequency, show smaller values as it closed to design flow rate. It is known that the excitations generated by the blade passage close the volute tongue can be decreased to a known value by means of increasing radial gap.

Vibration is one of the most serious problems in the pumping stations in Egypt. Pumping stations are subjected to many operational problems including mechanics and hydraulics problems affecting the performance and efficiency of the pumping stations. It is very important to avoid or overcome these problems to obtain maximum efficiency for the pumping station. Mechanical sources including unbalance, misalignment, bearing, resonance, and etc. problems. Pumping stations is sensitive to mechanical and hydraulic problems that lead to vibrations and which leading to resonance phenomena. Broch [11] there has been considerable interest in the maintenance techniques based on condition monitoring, with the analysis of vibration characteristics generated by machines, which makes it possible to determine whether the machinery is in good or bad condition [11]. Condition monitoring is defined as the collection, comparison and storage of measurements defining machine condition Biswas [12]. One of the objectives of Condition monitoring is to recognize damage that has occurred so that ample time is available to schedule repairs with minimum disruption to operation and production.

This research was initiated with the objective of studying the effect of adding short blades on pump performance and occurrence of pump vibration severity and bearing defect factor when adding short blades between the original impeller blades.

\section{Research Model}

The selected pump has a specific speed of 23.75 and an impeller with 7 blades was researched. Experiment and geometry variables under the design parameter were shown in Table 1. In order to investigate the effect of short blades length on the inner flow field and characteristics of the model pump, four short blades with different length was added between the original blades. 
Table 1. Specifications of centrifugal pump model

\begin{tabular}{|c|c|c|}
\hline \multicolumn{2}{|r|}{ Description } & $\begin{array}{l}\text { Radial pump with } \\
\text { volute casing }\end{array}$ \\
\hline \multirow{4}{*}{$\begin{array}{l}\text { Design operation } \\
\text { point }\end{array}$} & Flow rate, $Q$ & $50 \mathrm{~m}^{3} / \mathrm{hr}$ \\
\hline & Rotational speed, $n$ & $2900 \mathrm{rpm}$ \\
\hline & Delivery head, $H$ & $35 \mathrm{~m}$ \\
\hline & Specific speed, $n_{s}=n \sqrt{ } Q / H^{3 / 4}$ & $23.75\left(\mathrm{rpm}, \mathrm{m}^{3} / \mathrm{s}, \mathrm{m}\right)$ \\
\hline \multirow{4}{*}{$\begin{array}{l}\text { Impeller } \\
\text { dimensions }\end{array}$} & Number of blades, $z$ & 7 \\
\hline & Hub diameter, $\mathrm{d}_{\mathrm{N}}$ & $30 \mathrm{~mm}$ \\
\hline & Suction diameter, $\mathrm{D}_{1}$ & $92 \mathrm{~mm}$ \\
\hline & Impeller diameter, $\mathrm{D}_{2}$ & $165 \mathrm{~mm}$ \\
\hline \multirow{4}{*}{ Blade properties } & Number of meridional sections & 7 \\
\hline & Blade thickness & $20 \mathrm{~mm}$ \\
\hline & Inlet blade angle, $\beta_{1}$ & $19.8^{\circ}$ \\
\hline & Outlet blade angle, $\beta_{2}$ & $24.8^{\circ}$ \\
\hline
\end{tabular}

The 3D models of impeller and volute were generated by specialist modern software Cfturbo technique, the gap between impeller and volute was supplement to impeller. The impeller inlet and volute outlet were extended properly to reduce the effect of boundary conditions on inner flow. The meshes required for the calculations were generated and checked by using the CFD preprocessing package, GAMBIT. Due to the geometry of the pump is very complex, unstructured tetrahedral mesh is used. "EquiAngle Skew" and "EquiSize Skew" of the grid were all less than 0.95 , so the grid quality would be more homogeneously. Relativity test of grid element was done for each model with different short blade length. When the effect of grid number on pump characteristics is less than $1 \%$, it could be ignored. The grid numbers of volute and impellers with different short blade length are 490000 respectively. Figure (1) shows the 3D model and wall grid of the calculation region with 7 blades.
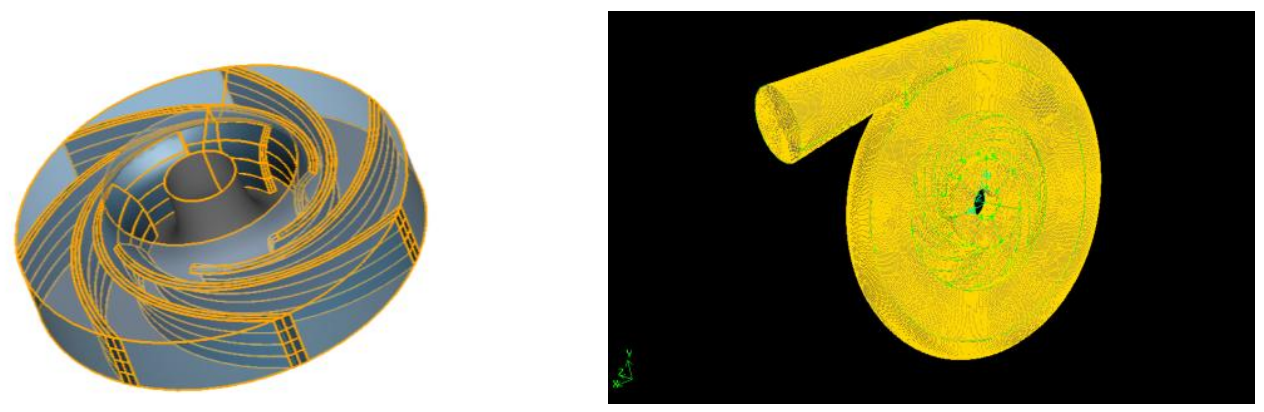

Fig. (1) 3-D model and wall grid of the impeller and volute

\section{NUMERICAL SIMULATION AND PERFORMANCE PREDICTION}

The numerical flow analysis permits the study of different parameters which are always difficult to measure experimentally. The performance of centrifugal pump changes with adding short blades length. The blade length factor $L_{b}$ is defined as the ratio between the mean length of short blade $L_{m s}$ to the mean length of blade $L_{m b}$ as shown in equation (1) and in Figure (2).

$L_{b}=\frac{L_{m s}}{L_{m d}}$

FLUENT under ANSYS Ver.14.5 [13] was selected to simulate the inner flow field. The standard $k-\varepsilon$ turbulence model and SIMPLEC algorithm are applied to solve the Unsteady Reynold Averaged Navier Stokes (URANS) equations. The simulation is unsteady and the sliding mesh technique is applied to take into account the impeller-volute interaction. Convergence precision of residuals is $10^{-5}$. 


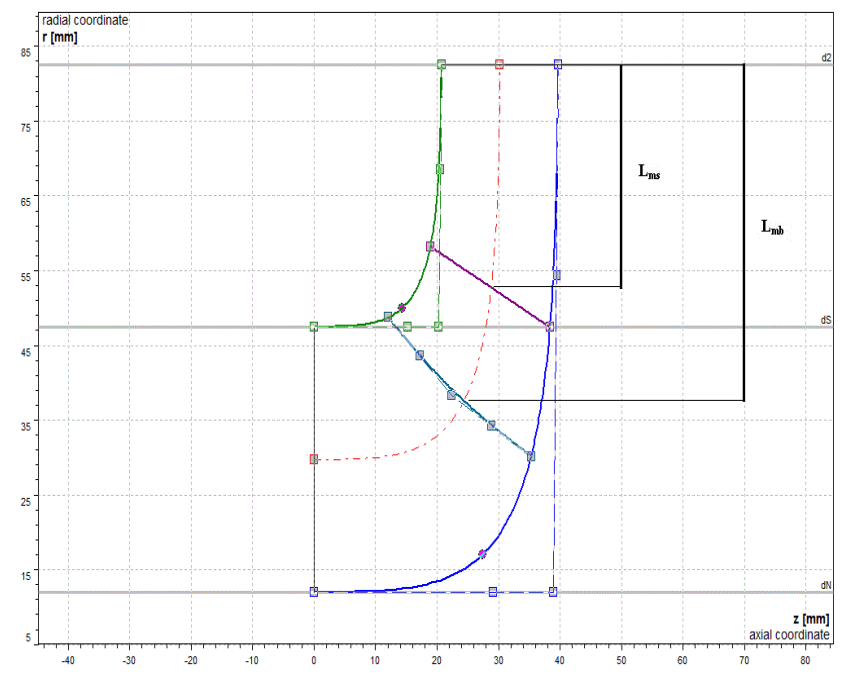

Figure (2) Blade length factor, $L_{b}$

\subsection{Boundary conditions}

Velocity inlet $u_{\text {in }}$ was selected as the inlet boundary condition and assumed uniform at the axis direction with its value equals to ratio of flow rate and inlet area.

$u_{\text {in }}=\frac{\text { Flow Rate }}{\text { Area }}=\frac{Q}{\frac{\pi}{4} \times D_{\text {in }}^{2}}$,

where $Q$ is the flow rate, $D_{\text {in }}$ is the pump inlet diameter. The turbulent condition at pump inlet can be described by turbulent kinetic energy $k$ and turbulent dissipation rate $\varepsilon$, they can be estimated by the following formula:

$k=0.005 u_{i n}^{2}$,

$\varepsilon=\frac{C_{\mu}^{\frac{3}{4}} k^{\frac{3}{2}}}{l}$,

where $l$ is the turbulent length scale, $l=0.07 D_{i n}$, and the pressure fluctuation coefficient, $C_{\mu}=0.09$. Outflow outlet was specified as outlet boundary condition, and flow rate weighting is set to be 1. As to wall boundary condition, no slip condition is enforced on wall surface and standard wall function is applied to adjacent region.

\subsection{Simulation and analysis of inner flow field}

\subsubsection{Static pressure distribution}

The static pressure distributions at the midspan of the pumps with different short blade length factor, $L_{b}$ are shown in Figure (3).

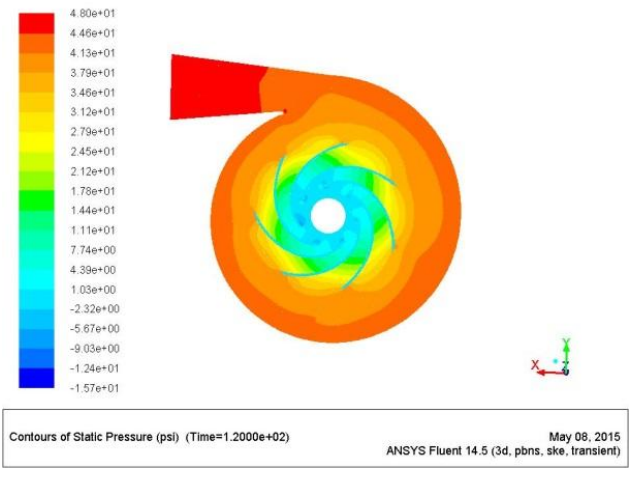

(a) Original impeller without short blades

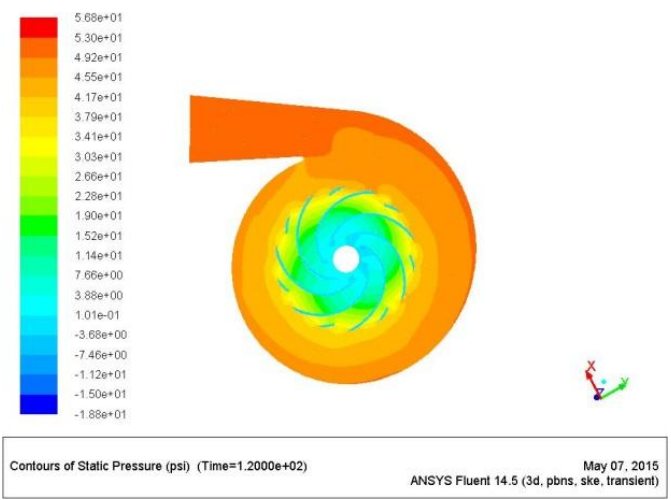

(b) $L_{b}=0.16$ 


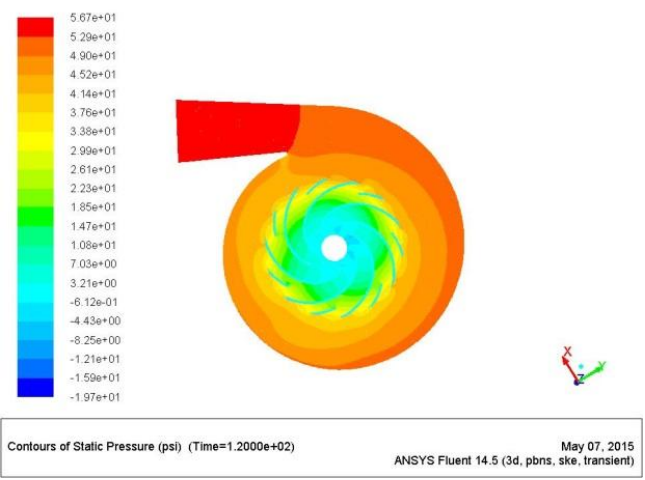

(c) $L_{b}=0.25$

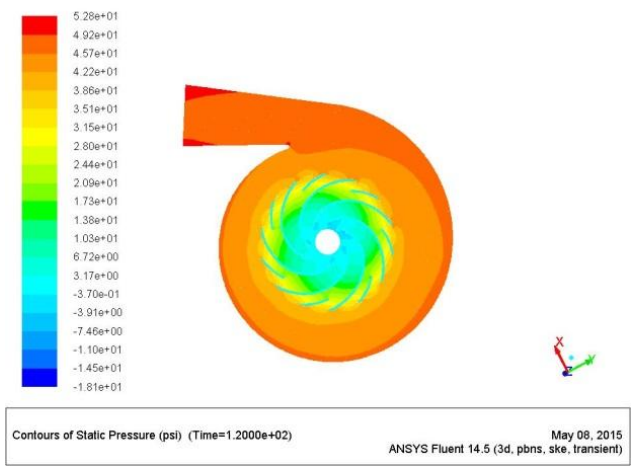

(d) $L_{b}=0.3$

Figure (3) Static pressure distributions at midspan for different short blade length (psi)

From Figure (3), it can be seen clearly that the static pressure increasing with short blades adding between the original blades. Consequently, the static pressure increases with increase the short blades length. The maximum pressure of the original impeller without short blade is $48 \mathrm{psi}$, while the maximum pressure values with additional short blades, $L_{b}=0.3,0.25$ and 0.16 are 49.2, 56.7 and 53 psi respectively. The pressure increases gradually along stream wise direction within impeller blade-to-blade passage. Figure (3-b to d) also shows that, the pump configurations with short blades, presents a more homogeneous circumferential pressure distribution except near the volute tongue which generates a zone of largest pressure gradient contributing to an unequal flow distribution in the blades. Furthermore, for different short blades length, the static pressure gradually increase from impeller inlet to outlet, the static pressure on pressure side is evidently larger than that on suction side at the same impeller radius. When short blades are added to the impeller, there is a significant decrease of pressure fluctuation. With the increase of short blades length, the static pressure at volute outlet grows all the time, and the uniformity of static pressure distributions at screw section become worse and worse, but at diffusion section become better and better. The impellers with different blades length all have an obvious low pressure area at the suction side of blade entrance. With the increase of blade length, the area of low pressure region grows continuously, which indicates that the short blades have a significant effect on characteristics of centrifugal pumps. The model was calibrated by comparison the exit pressure from the simulation results and compared with the experimental values gained from the experimental verifications at each short blade length.

\subsubsection{Absolute velocity distribution}

The contours of velocity distributions at front shroud of impellers with different blade number are shown in Figure (4). From Figure (4), it can be seen that the velocity increase with adding short blades and the maximum increasing at short blades with $L_{b}=0.25$. The maximum velocity without short blades impeller reach to $22 \mathrm{~m} / \mathrm{s}$ but in the case of adding short blades with, $L_{b}=0.25$ the magnitude of flow velocity reach to $25.8 \mathrm{~m} / \mathrm{s}$. This means that, the short blades is a significant effect of impeller flow rate, furthermore when increase the short blades length to, $L_{b}=0.3$ the area between two blades is small and increases the mixture loss. On the other hand in the case of short blades length, $L_{b}=0.16$ it is observed that the absolute velocity distribution is not uniform in the blade passage across the impeller width.

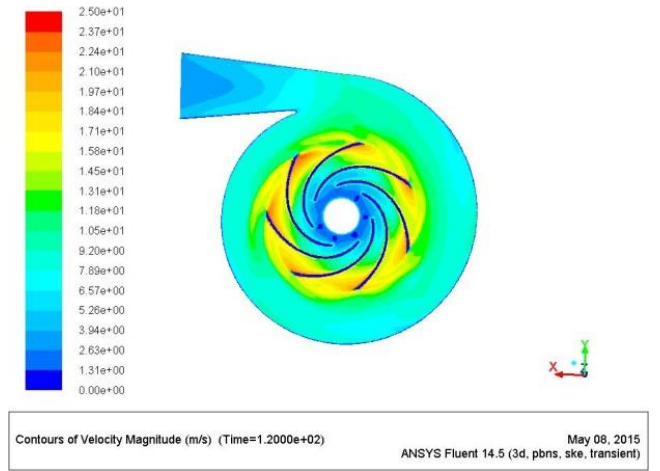

(a) Original impeller without short blades

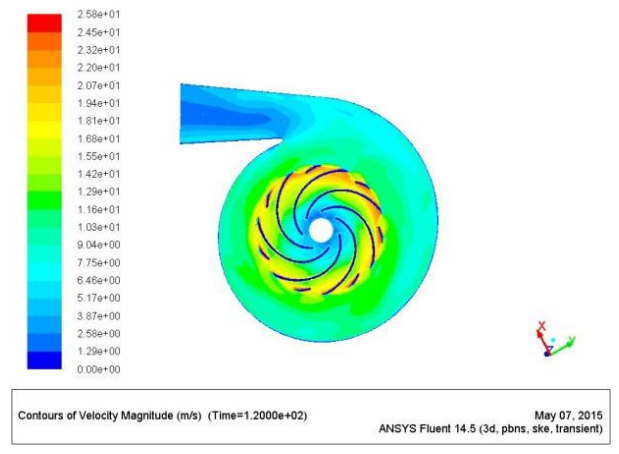

(b) $L_{b}=\mathbf{0 . 1 6}$ 


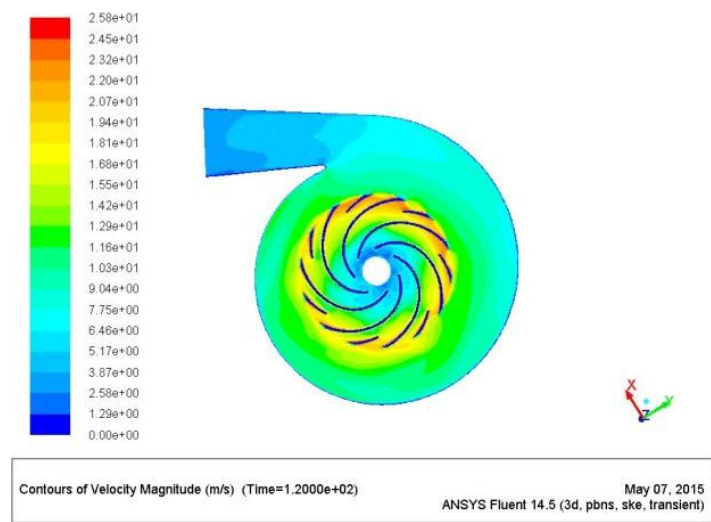

(c) $L_{b}=\mathbf{0 . 2 5}$

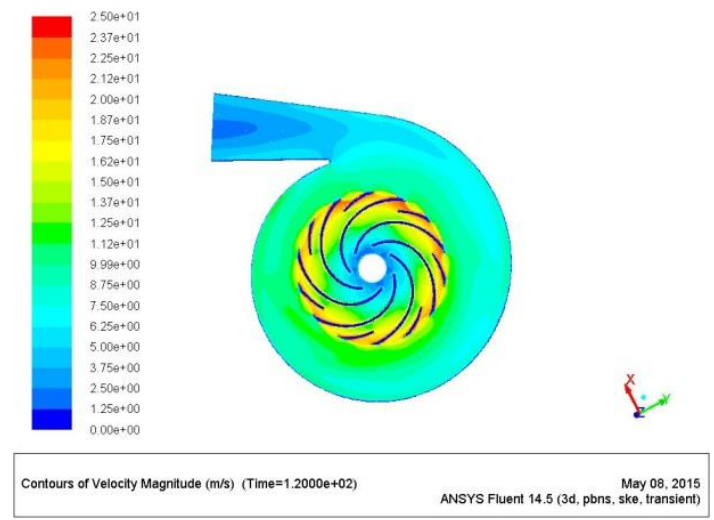

(d) $L_{b}=0.3$

Figure (4) Velocity distributions at front shroud for different short blade length $(\mathrm{m} / \mathrm{s})$

\subsection{Head and Efficiency Prediction algorithm}

Head $H$ of centrifugal pump is calculated as follows [14]:

$H=\frac{P_{\text {out }}-P_{\text {in }}}{\rho g}$,

where $P_{\text {in }}$ is the total pressure of impeller inlet, $P_{\text {out }}$ is the total pressure of volute outlet, $\rho$ is density of the fluid, and $g$ is the gravity acceleration.

Hydraulic efficiency $\eta_{h}$ is calculated as follows:

$\eta_{h}=\frac{\rho g Q H}{M \omega}$,

where $M$ is the impeller torque, $\omega$ is the angle velocity.

Volume efficiency $\eta_{v}$ is calculated as follows:

$\eta_{v}=\frac{1}{1+0.68 n_{s}^{-2 / 3}}$,

Total efficiency $\eta$ is calculated as follows:

$\eta=\left[\frac{1}{\eta_{h} \eta_{v}}+\frac{\Delta P_{d}}{P_{e}}+0.03\right]^{-1}$,

where $P_{\mathrm{e}}$ is the water power and $P_{\mathrm{e}}=\rho g Q H, \Delta P_{d}$ is the disk friction loss, calculation method is described in Ref. [15].

The predicted head and efficiency of model pumps with different short blade length factor, $L_{b}$ under design condition are shown in Table 2. The maximum values of predicted head and efficiency was achieved at $L_{b}=0.25$.

Table 2. Predicted values of head and efficiency

\begin{tabular}{|c|c|c|c|c|c|}
\hline Parameter & $\begin{array}{c}\text { Impeller without } \\
\text { short blades }\end{array}$ & $\begin{array}{c}L_{b} \\
=0.16\end{array}$ & $\begin{array}{c}L_{b} \\
=0.2\end{array}$ & $\begin{array}{c}L_{b} \\
=0.25\end{array}$ & $\begin{array}{c}L_{b}= \\
0.3\end{array}$ \\
\hline Predicted head, $H(\mathrm{~m})$ & 33.77 & 37.3 & 38.1 & 39.9 & 34.62 \\
\hline Predicted efficiency, $\eta(\%)$ & 73.1 & 77.7 & 78.7 & 81.2 & 75.8 \\
\hline
\end{tabular}

\section{Experimental Verification}

The characteristics of the model pump with different blades length were tested in Mechanical and Electrical Research Institute, National Water Research Center, in order to examine the predicted results calculated by using the CFD numerical simulation methods. The experiments were conducted in an open test loop, which consists of a reservoir open to air, a suction valve, a discharge pipe and a discharge valve. The pump was driven by $15 \mathrm{hp}$ electric motor with $2900 \mathrm{rpm}$. The flow rate was adjusted with the discharge valve and measured by using an ultrasonic flow meter. The pressure was measured at two locations, the suction and discharge 
of the tested pump by vacuum gauge and pressure gauge. The electric power consumption was measured by using three phase power analyzer. The break horse power of pump shaft was measured by using torque meter instrument. The experimental set for pump is shown in Figure (5). The experimental impellers with different blade number were made from commercial steel by using rapid prototyping, as shown in Figure (6).

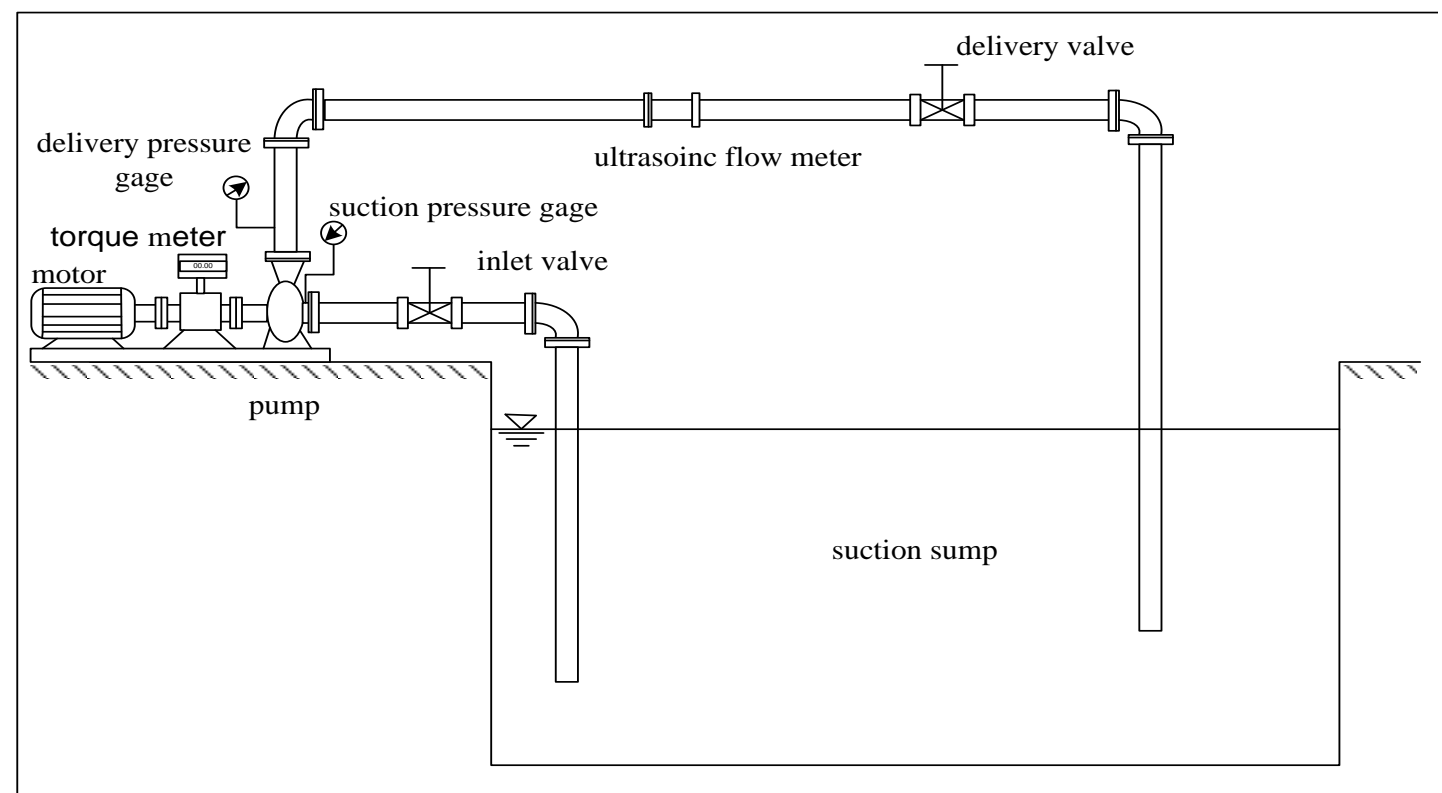

Figure (5) Experimental setup for pump test

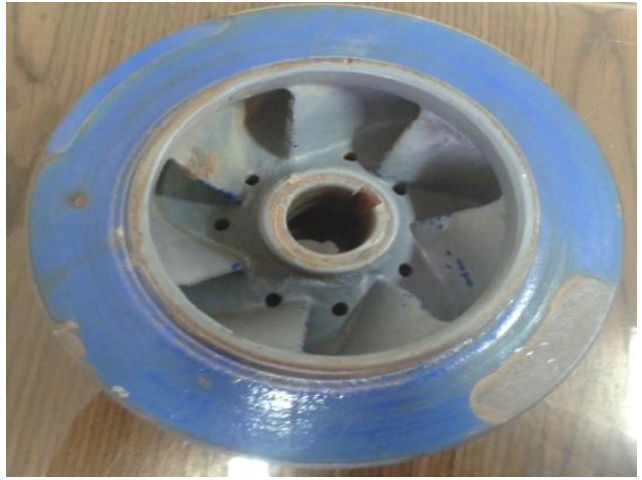

(a) Original impeller with 7 blades

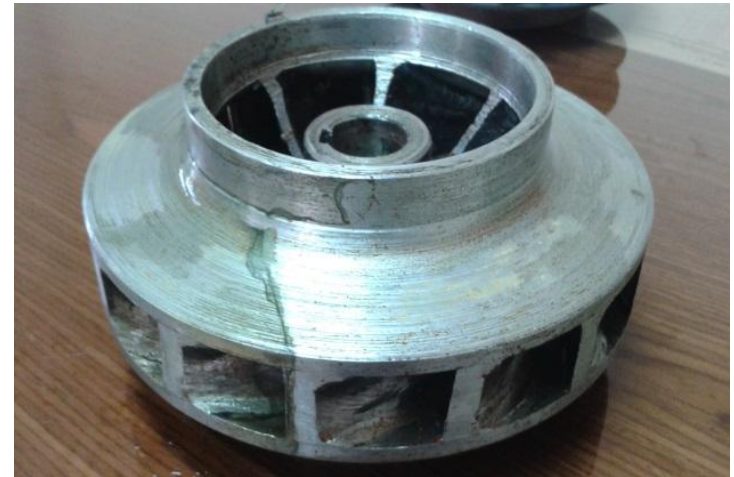

(b) Modified impeller with 7 short blades, $L_{b}=0.25$

Figure (6) Experimental impellers (a) original impeller, and (b) impeller with short blades, $L_{b}=0.25$

The test process confirms to the pump experiment standard completely, and the Head curve, pump shaft power curve and pump efficiency curve at different flow condition can be obtained. The experimental data of model pumps with different short blades length under design condition are shown in Figure (7) and Table 3.

From Figure (7), it can be illustrated that, the pump flow rate increase with impellers short blades from 85 to $111 \mathrm{~m}^{3} / \mathrm{hr}$, while the power consumption decrease in the impellers of short blades. Consequently the overall efficiency increases due to insert the short blades between the original blades. 


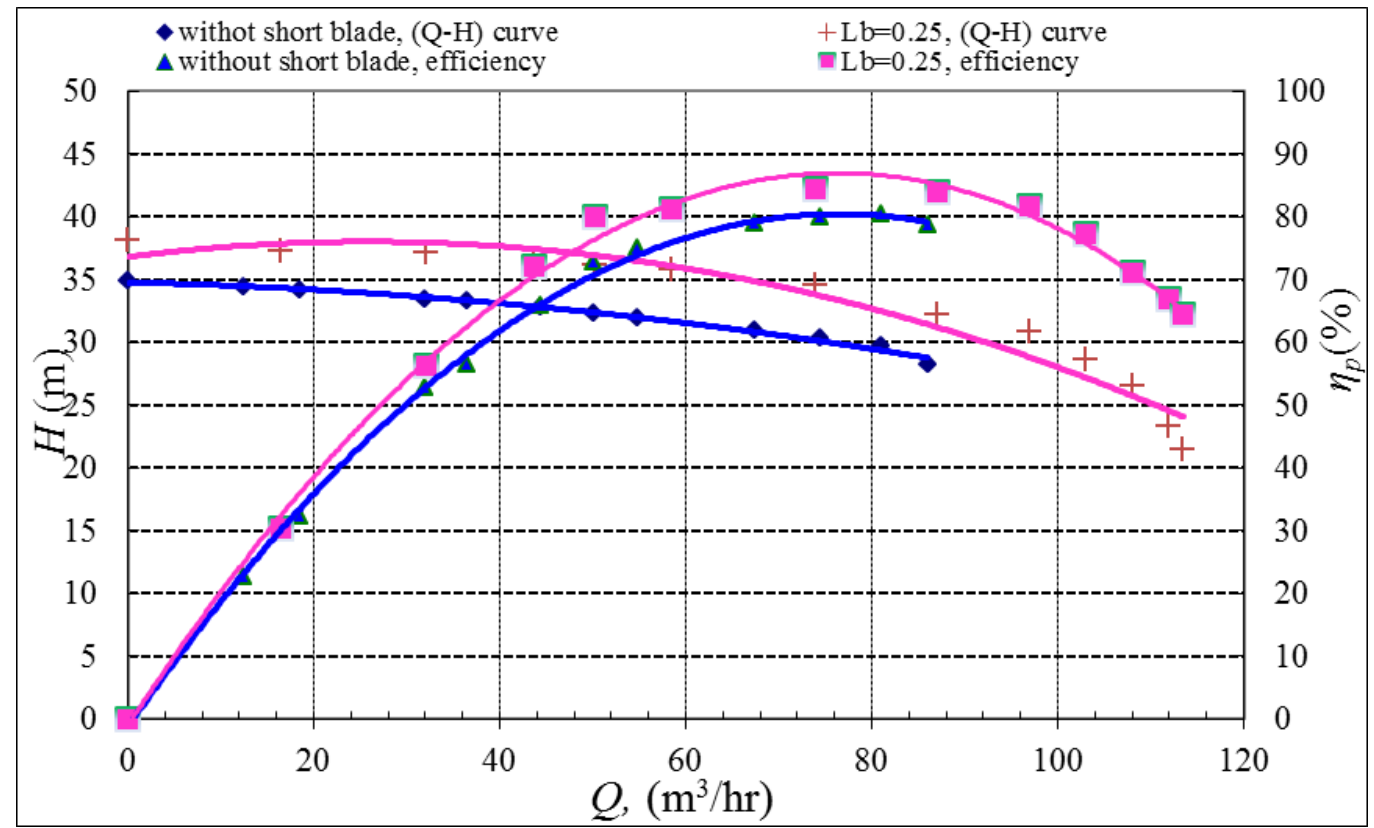

Figure (7) Experimental results of original impeller without short blades and impeller with different short blades lengths, $L_{b}$

Table 3. Experimental values

\begin{tabular}{|c|c|c|c|}
\hline Blade length factor, $L_{b}=L_{m s} / L_{m b}$ & $\begin{array}{c}\text { Head, } \mathrm{H} \\
(\mathrm{m})\end{array}$ & $\begin{array}{c}\text { Pump shaft } \\
\text { power, }(\mathrm{kw})\end{array}$ & $\begin{array}{c}\text { Pump Efficiency, } \\
\eta_{\mathrm{p}}(\%)\end{array}$ \\
\hline impeller without short blades & 32.36 & 5.95 & 72.9 \\
\hline 0.16 & 34.82 & 6 & 75.52 \\
\hline 0.25 & 36.14 & 6.05 & 79.85 \\
\hline 0.3 & 33.75 & 6.15 & 73.44 \\
\hline
\end{tabular}

The experimental results and predicted results of characteristics of model pumps with different short blades length were compared in Figure (8). From Figure (8), it can be illustrated that the head of model pump grows with the increase of short blade length reach the maximum values at $L_{b}=0.25$ and then decreased, and the increase amplitude of head is unequal sized. When the blade length factor, $L_{b}$ is 0.25 , the head and the efficiency of model pump obtains the maximum value, while the main length factor, $L_{b}$ is 0.3 the pump efficiency values less than the efficiency at other blade length factors, $L_{b}$. For impeller with additional short blades between the main blades, $\mathrm{H}$ increased by $3.78 \mathrm{~m}(11.68 \%)$, and $\eta$ by $(6.95 \%)$. The power consumption in the case of blade length is 0.25 of the impeller blade length; approximately constant compared with the total energy consumption without impeller short blades as shown in Table 3. From pump characteristics as shown in Figure (8), which indicate that, the maximum efficacy of centrifugal pump occurs at $L_{b}=0.25$. The maximum discrepancies of prediction results for head, efficiency, are $9.4 \%$, and $1.66 \%$, respectively. 


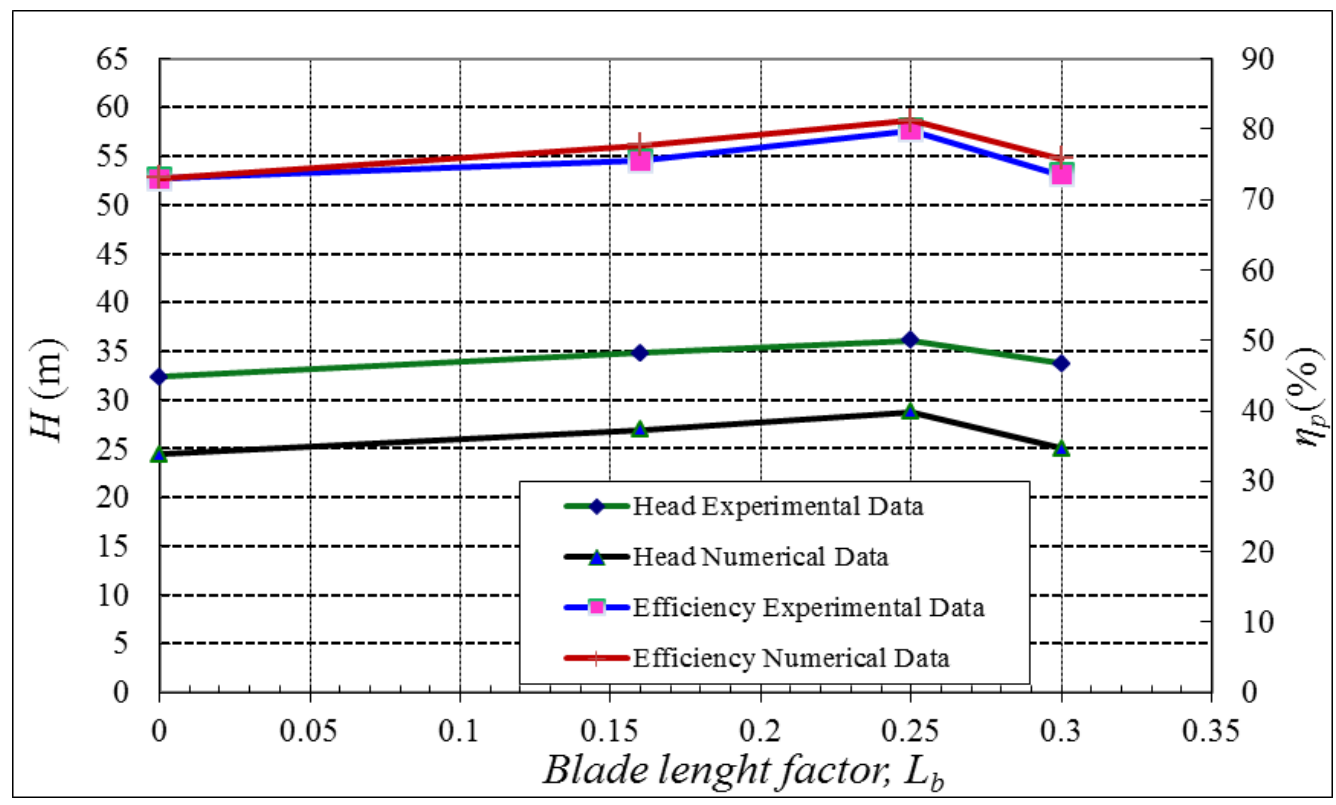

Figure (8) Comparison between experiment data and CFD results

\section{DYNAMIC ANALYSIS}

Dynamic Analysis is done to indicate the severity of vibration which it is the basis to judge the status of machinery if the conditions within the international standard or not (ISO 108163) [3]. While, frequency analysis is usually done to identify unwanted high frequencies for each element in the pump system, to define the existing frequencies and determine the level of vibration at each specific frequency, to determine the sources of vibration, and control the vibration levels. Measurements included the overall vibration velocity, vibration acceleration, and bearing defect factor. Measurements were done at 9 locations on all units in three directions axial, horizontal, and vertical perpendicular, as shown in Figure (9) and compared the results with standards of machines (ISO 10816-3) (Figure (10)). The frequency analysis was also performed at low and high frequencies.

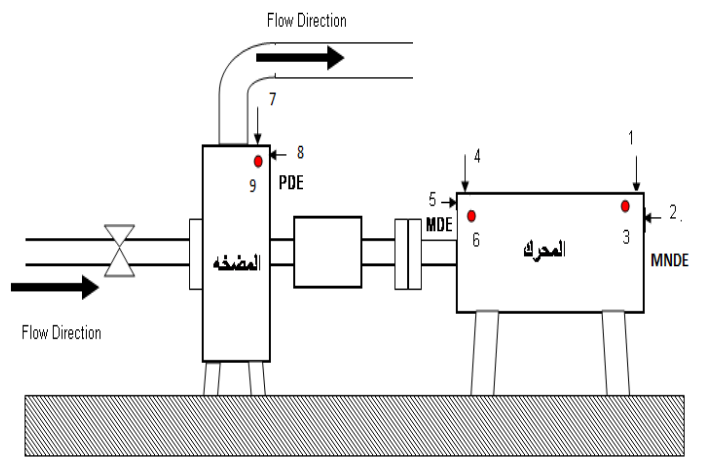

Figure (9) Measurement locations

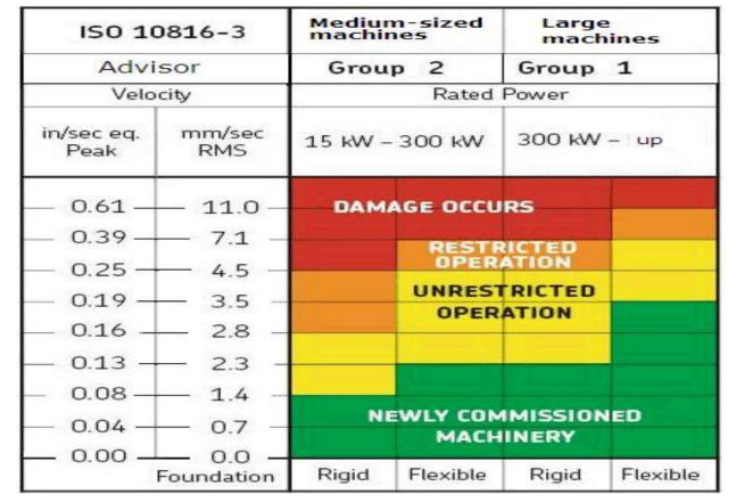

Figure (10) ISO Standard 10816-3

Results of measurements show that the vibration level is within the tolerance of ISO standards (ISO10816-3) [16]. In case of modification of impeller by adding short blade with length ratio, $L_{b}=0.25$. The maximum level of vibration reached up to $1.32 \mathrm{~mm} / \mathrm{sec}$ on the pump side, as shown in Table (4). The measurements results indicated that the vibration level little bit high vibration level on the pump side and it's higher than the original impeller without short blades. These levels are within acceptable rang according to ISO Standard 10816-3 which recommended that for machines with power less than $300 \mathrm{kw}$ level of vibration in RMS velocity is good level until $1.4 \mathrm{~mm} / \mathrm{sec}$, level of vibration in RMS velocity is allowable level until $2.8 \mathrm{~mm} / \mathrm{sec}$, level of vibration in RMS velocity is restricted operation level until 4.5 $\mathrm{mm} / \mathrm{sec}$ and level of vibration in RMS velocity is damage level if it reached greater than 7.1 
$\mathrm{mm} / \mathrm{sec}$, as shown in Figure (10). Consequentially in the case of blade length ratio, $L_{b}=0.25$, the bearing defect factors were within the acceptable range and acceleration. These levels are within acceptable rang according to ISO Standard 10816-3 which recommended that for machines with power less than $300 \mathrm{kw}$ level of vibration in overall acceleration is good level until 1, level of vibration in overall acceleration is allowable level until 1.5, level of vibration in overall acceleration is damage level if it reached greater than 1.5.

Table. 4 Overall vibration levels measured in all measurement cases

\begin{tabular}{|c|c|c|c|c|c|c|c|c|c|}
\hline \multirow[b]{2}{*}{$\begin{array}{l}\text { Location } \\
\text { Measurem } \\
\text { ents }\end{array}$} & \multicolumn{3}{|c|}{ Overall Acceleration } & \multicolumn{3}{|c|}{$\begin{array}{l}\text { Overall Velocity } \\
(\mathrm{mm} / \mathrm{sec})\end{array}$} & \multicolumn{3}{|c|}{$\begin{array}{l}\text { Bearing Defect } \\
\text { Factor (DEF) }\end{array}$} \\
\hline & $\begin{array}{l}\text { impell } \\
\text { er } \\
\text { withou } \\
\text { t short } \\
\text { blades }\end{array}$ & $\begin{array}{c}L_{b}= \\
0.25\end{array}$ & $\begin{array}{c}L_{b}=0 . \\
3\end{array}$ & $\begin{array}{l}\text { impell } \\
\text { er } \\
\text { withou } \\
\text { t short } \\
\text { blades }\end{array}$ & $\begin{array}{c}L_{b}=0 . \\
25\end{array}$ & $\begin{array}{c}L_{b}=0 . \\
3\end{array}$ & $\begin{array}{l}\text { Impe } \\
\text { ller } \\
\text { with } \\
\text { out } \\
\text { short } \\
\text { blade }\end{array}$ & $\begin{array}{c}L_{b}=0 . \\
25\end{array}$ & $\begin{array}{c}L_{b}=0 \\
.3\end{array}$ \\
\hline \multirow{3}{*}{$\begin{array}{c}\text { Motor } \\
\text { None } \\
\text { Drive End } \\
\text { (MNDE)A } \\
\text {,V, H }\end{array}$} & 0.56 & 0.6 & 0.77 & 0.77 & 0.89 & 1.61 & 2.89 & 3.01 & 4.01 \\
\hline & 0.52 & 0.66 & 0.84 & 0.8 & 0.85 & 1.53 & 3.1 & 3.5 & 4.61 \\
\hline & 0.51 & 0.59 & 0.89 & 0.89 & 0.95 & 1.33 & 2.45 & 3.5 & 4.53 \\
\hline \multirow{3}{*}{$\begin{array}{c}\text { Motor } \\
\text { Drive End } \\
(\mathrm{MDE}) \\
\mathrm{A}, \mathrm{V}, \mathrm{H}\end{array}$} & 0.6 & 0.71 & 1.01 & 0.91 & 1.01 & 1.09 & 3.45 & 4.01 & 4.63 \\
\hline & 0.54 & 0.66 & 1.1 & 0.93 & 1.1 & 2.11 & 2.58 & 3.89 & 4.54 \\
\hline & 0.70 & 0.73 & 1.13 & 0.92 & 0.96 & 2.3 & 2.9 & 3.99 & 5.01 \\
\hline \multirow{3}{*}{$\begin{array}{c}\text { Pump } \\
\text { Drive End } \\
\text { (PDE) } \\
\mathrm{A}, \mathrm{V}, \mathrm{H}\end{array}$} & 0.55 & 0.78 & 1.41 & 1.01 & 1.2 & 2.46 & 3.01 & 4.2 & 6.23 \\
\hline & 0.58 & 0.8 & 1.53 & 0.89 & 1.3 & 2.77 & 3.2 & 4.5 & 6.51 \\
\hline & 0.6 & 0.8 & 1.55 & 0.91 & 1.32 & 2.78 & 3.45 & 4.55 & 6.41 \\
\hline
\end{tabular}

From Table (4) dynamic analysis concluded that when added short blades with length ratio $L_{b}=0.3$, the vibration level severity increase to reach $2.78 \mathrm{~mm} / \mathrm{s}(175 \%)$ compared to impeller without short blades $(1.01 \mathrm{~mm} / \mathrm{s})$, but these values with the acceptable range according to ISO 10316-3. High frequency analysis, show that the bearing affected by adding short blades. From the previous dynamic analysis it can be concluded that when added short blades with length ratio $L_{b}=0.25$, the vibration level severity increase to reach $1.32 \mathrm{~mm} / \mathrm{s}(30 \%)$ compared to impeller without short blades $(1.01 \mathrm{~mm} / \mathrm{s})$, but these values with the acceptable range according to ISO 10316-3. While at impeller without short blades the vibration amplitude reach to $1.01 \mathrm{~mm} / \mathrm{s}$, this value excellent according to ISO 10316-3. 


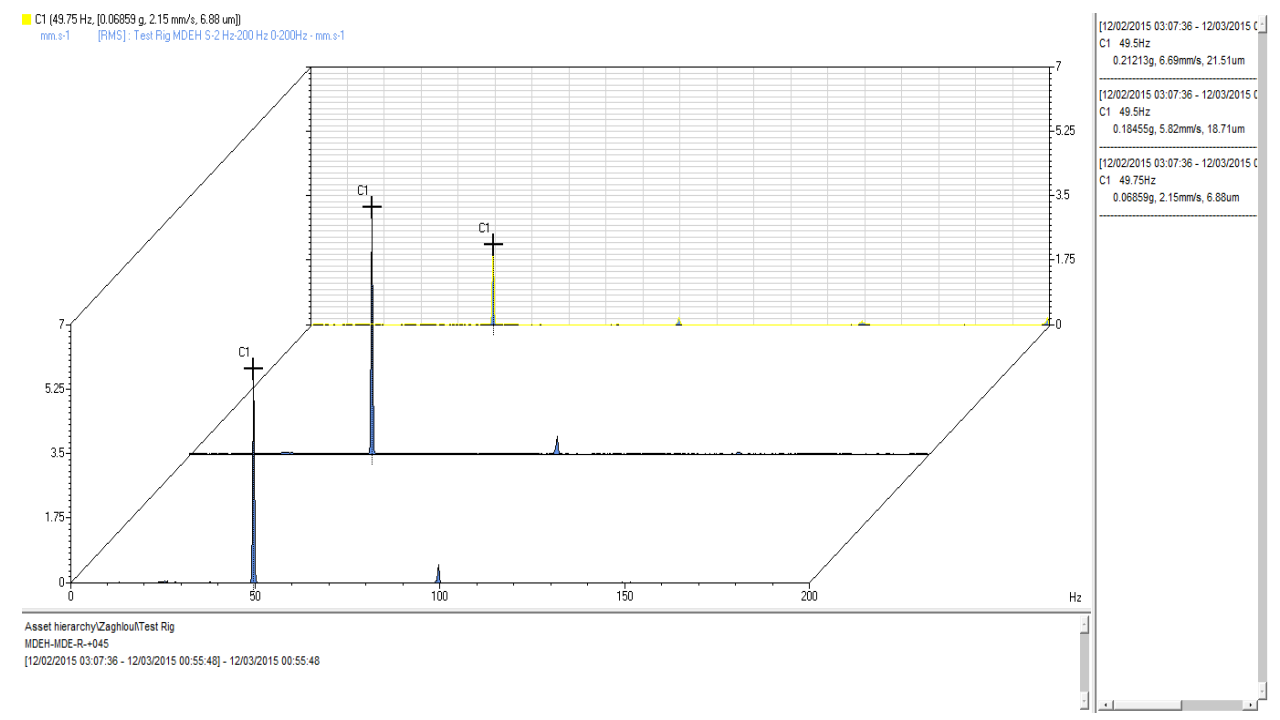

Figure (11) Vibration amplitude at studied cases

Figure (11) shows that, the vibration amplitude reaches to $1.01 \mathrm{~mm} / \mathrm{s}$ in the case of impeller without short blades $(\mathrm{C} 1)$, while in the case of add short blades with $L_{b}=0.3$ the vibration severity amplitude increase to $2.78 \mathrm{~mm} / \mathrm{s}$, this value refers to dynamic unbalance when adding short blades (C2) between the original impeller blades. After the second modification by adding short blade (C3) with length factor, $L_{b}=0.25$ the vibration intensity decreases to 1.32 $\mathrm{mm} / \mathrm{s}$ compared with the first modification, $L_{b}=0.3$. The case of $L_{b}=0.25$ gives the best values according to vibration analysis as mention before in the hydraulic performance.

\section{CONCLUSIONS}

The effects of short blades length on inner flow and characteristics of centrifugal pump were studied using numerical simulation model and subsequent experimental verification. The main research conclusions are below.

1. When short blades are added to the impeller, a significant decrease in pressure fluctuation was observed and the area of low pressure region at the suction of blade inlet also grows continuously. Simulation results also showed improper uniformity for the static pressure distribution at screw section, while at the diffusion section the uniformity become more profound.

2. The impellers with different short blades length all have an obvious low pressure area at the suction side of blade inlet. With the increase of blade length, the area of low pressure region grows continuously, which indicates that the short blades have a significant effect on characteristics of centrifugal pumps.

3. The velocity increase with adding short blades and the maximum increasing at short blades with $L_{b}=0.25$. The maximum velocity without short blades impeller reached up to $22 \mathrm{~m} / \mathrm{s}$ but in the case of adding short blades with, $L_{b}=0.25$, the magnitude of flow velocity was $25.8 \mathrm{~m} / \mathrm{s}$.

4. For impeller with additional short blades between the main blades, the head increased by $3.78 \mathrm{~m}(11.68 \%)$, and the predicted efficiency by (6.95\%). The power consumption in the case of blade length is 0.25 which is approximately constant compared with the total energy consumption without impeller short blades.

5. With the increase of short blades length, the head of centrifugal pump grows all the time, the change regulations of efficiency and power consumption are complex, but there is an optimum value for the best efficiency and power consumption characteristics, the optimum short blades length of the model pump in this paper for power consumption and efficiency is 0.25 .

6. Comparison between experimental and the time averaged numerical results shows that CFD results are in good agreement with those of experimental and can be used in the performance prediction and optimization of centrifugal pumps with additional short blades. 
7. When short blades were added to the impeller, the vibration level severity at $L_{b}=0.3$ increased to $2.78 \mathrm{~mm} / \mathrm{s}(175 \%)$ compared to impeller without short blades $(1.01$ $\mathrm{mm} / \mathrm{s}$ ). These values with in the alarm rang according to ISO 10316-3 and might cause impeller dynamic instability. High frequency analysis show that, the bearing was affected by adding short blades

8. When short blades were added to the impeller, the vibration level severity at $L_{b}=0.25$ increases to $1.32 \mathrm{~mm} / \mathrm{s}(30 \%)$ compared to impeller without short blades $(1.01 \mathrm{~mm} / \mathrm{s})$, but these values fall within the acceptable range according to ISO 10316-3.

Generally we recommended that, the impellers of centrifugal pumps should be having the short blades between the original blades with the length factor equal to $L_{b}=0.25$ because this added blades improve the pump efficiency without side effect of dynamic performance.

\section{REFERENCES}

[1] M. Harano, K. Tani, and S. Nomoto, "Practical application of high-performance francisturbine runner fitted with splitter blades at ontake and shinkurobegawa no. 3 power stations of the Kansai electric power Co., Inc”, Hitachi Review, Volume 55, no. 3, pp. 109-113, 2006.

[2] G. Mustafa, P. Yasar, and S. Yakup,"Energy saving in a deep well pump with splitter blade", Energy Conversion and Management, Volume 47, no. 5, pp. 638-651, 2006.

[3] J. P. Solano, V. Pinilla, G. Paniagua, S. Lavagnoli, and T. Yasa, "Aero-thermal investigation of a multi-splitter axial turbine", International Journal of Heat and Fluid Flow, Volume 32, no. 5, pp. 1036-1046, 2011.

[4] Mois'es Solis, Farid Bakir, Sofiane Khelladi, and Ricardo Noguera," Numerical study on pressure fluctuations reduction in centrifugal pumps: influence of radial gap and splitter blades", International Scholarly Research Network ISRN Mechanical Engineering, Volume 2011, 14 pages.

[5] Yang Sun-Sheng, Kong Fan-Yu, Fu Jian-Hui, and Xue Ling," Numerical research on effects of splitter blades to the influence of pump as turbine", International Journal of Rotating Machinery, Volume 1, 2012.

[6] R. Spence and J. Amaral-Teixeira, "Investigation into pressure pulsations in a centrifugal pump using numerical methods supported by industrial tests", Computers and Fluids, pp. 1$15,2007$.

[7] M. Asuaje, F. Bakir, S. Kouidri, F. Kenyery, and R. Rey, "Numerical modelization of the flow in centrifugal pump: volute influence in velocity and pressure fields", International Journal of Rotating Machinery, Volume 3, pp. 244-255, 2005.

[8] G. Kergourlay, M. Younsi, F. Bakir, and R. Rey, "Influence of splitter blades on the flow field of a centrifugal pump: test-analysis comparison", International Journal of Rotating Machinery, Volume 1, Article ID 85024, 2007.

[9] H. Miyamoto, Y. Nakashima, and H. Ohba, "Effects of splitter blades on the flows and characteristics in centrifugal impellers", JSME International Journal, Volume 35, no. 2, pp. 238-246, 1992.

[10] J. L. Parrondo-Gayo, J. Gonz'alez-P'erez, and J. Fern'andez-Francos, "The effect of the operating point on the pressure fluctuations at the blade passage frequency in the volute of a centrifugal pump", Journal of Fluids Engineering, Transactions of the ASME, Volume 124, no. 3, pp. 784-790, 2002.

[11] Broch. J. T. "Mechanical vibrations and shock measurement", Bruel \& Kjaer, $2^{\text {nd }}$ edition, 1984.

[12] R. K. Biswas "Vibration based condition monitoring of rotating machines", national conference on condition monitoring [NCCM-2006] December 2006 pp. 34-40, 2006.

[13] ANSYS, "Fluent user document, version 14.5", ANSYS Europe, 2012.

[14] TAN Minggao, YUAN Shouqi, and LIU Houlin, "Numerical research on performance prediction for centrifugal pumps", Chinese Journal of Mechanical Engineering, 23(1), pp. 2126, 2010.

[15] TAN Minggao, "Prediction research on energy characteristics for centrifugal pumps", Zhenjiang: Jiangsu University, 2008.

[16] ISO 10816-1, "Mechanical vibration - evaluation of machine vibration by measurements on non-rotating parts", Part 1, General Guidelines 1995. 